DOI: 10.1590/permusi2015a3107

\title{
Aprendizagem musical na maturidade: diálogo entre teoria e prática
}

\author{
Andréa Cristina Cirino (UFMG, Belo Horizonte, MG) \\ accirino@terra.com.br
}

\begin{abstract}
Resumo: Esse trabalho apresenta uma síntese parcial da pesquisa de mestrado concluída em 2010, e tem como propósito discutir o significado de aprendizagem musical e sua relação com a teoria e a prática, levando em conta a intenção e a habilidade musical de adultos maduros. Sob esse enfoque qualitativo com técnicas de etnografia escolar, o artigo traz os relatos de oito alunos com idade a partir de 50 anos, que participaram de entrevistas semiestruturadas no decorrer do curso de extensão Apreciação e Musicalização na Maturidade - UFMG. Os resultados procedem da análise interpretativa do conteúdo, com base nos argumentos de SWANWICK (2003; 1996) e GREEN (2005). As considerações finais refletem sobre a importância de se adequar métodos de aprendizagem musical para esta faixa etária, conjugando teoria básica e atividades práticas conforme as possibilidades e a experiência do aprendiz.
\end{abstract}

Palavras-chave: aprendizagem musical para adultos; iniciantes em música na maturidade; significado musical e experiência de aprendizagem; teoria e prática musical.

\section{Musical learning in maturity: dialogue between theory and practice}

\begin{abstract}
This work presents a partial synthesis of the master's research concluded in 2010, and aims at discussing the meaning of musical learning and its relation to theory and practice, taking into account the intention and musical ability of mature adults. Under this qualitative approach with techniques of educational ethnography, the paper brings the reports of eight students over 50 years old who participated of semi-structured interviews during the community course Appraising and Musicalization in Maturity - UFMG. The results derive from the interpretative analysis of content, based on the ideas of SWANWICK $(2003 ; 1996)$ and GREEN (2005). The final considerations consider the importance of adapting methods of musical learning for this age range, combining basic theory and practical activities in accordance to the possibilities and experience of the learner.
\end{abstract}

Keywords: musical learning for adults; older beginners in music; musical meaning and learning experience; music theory and practice.

\section{1 - Introdução}

Atualmente diversos estabelecimentos de ensino proporcionam meios de inclusão às pessoas na maturidade ${ }^{1}$, que pretendem estudar música. Embora existam poucos relatos referentes ao aprendizado de adultos maduros em curso formal de música, há instituições que oferecem oficina de música em sua grade curricular. Além do curso de extensão Apreciação e Musicalização na Maturidade, da UFMG, temos como exemplo a Universidade Aberta à Terceira Idade (UnATI) em diversas cidades brasileiras, o Centro Cultural Pró-Música de Juiz de Fora, e o Programa da Maturidade na Faculdade Estácio de Sá - BH.

Acredita-se que, independentemente da idade, cada indivíduo tem seu potencial a ser explorado, sendo a atividade musical compensatória para experiências que permitem não só uma ampliação de conteúdos em diversas áreas do conhecimento, mas a integração entre pensamento e emoção (LUZ, 2008; SWANWICK, 2003). 
DEBERT (2004, p.132) ainda enfatiza: "Cada momento vivido é uma nova experiência e em qualquer idade há muito o que aprender". Desse modo, ainda que um aluno maduro apresente dificuldades em apreender conhecimentos considerados simples pelo professor, isso não determina que ele não possa ser educado musicalmente.

Nessa perspectiva, podemos supor que todo indivíduo tem a capacidade de ser musical e de vivenciar a música, prevalecendo a ideia de que tais habilidades podem ser adquiridas em qualquer período da vida (PENNA, 1990; ${ }^{2}$ SLOBODA, 2008). Segundo LUZ (2008, p.40-41), "a ideia de que se alfabetizar na linguagem sonora é possível em qualquer idade, transforma-se numa realidade”. Desse modo, é importante observar que a aula de música para pessoas maduras é capaz de propiciar um ambiente cultural que compartilha conhecimentos.

Dentro desse panorama, a musicalização pode ser concebida como etapa inicial da aprendizagem musical, pois envolve condições básicas para se trabalhar a audição, as definições dos elementos musicais, assim como a expressividade do aprendiz. Conforme GAINZA (1988, p.24), os adultos também são capazes de manifestar reações específicas através da captação sonora e dos processos expressivos consequentes da musicalização. Porém, qual o sentido de aprendizagem musical para os alunos maduros? O que eles querem aprender? Quais são as propostas educacionais para essa faixa etária?

Com base nas conjecturas e concepções relatadas pelos participantes do curso Apreciação e Musicalização na Maturidade, a contextualização sobre o assunto tem por finalidade discutir o significado da aprendizagem musical e sua relação com o aspecto teórico-musical e as atividades práticas durante o ensino. Considerando a aplicação interdisciplinar no estudo de música, também são expostos argumentos de diversas áreas, como pedagogia, psicologia, sociologia e educação musical. De acordo com SEKEFF (2002, p.160), a interface musical, articulada pela comunicação, permite harmonizar ciência e arte, promovendo o diálogo sociocultural.

\section{2 - Procedimentos metodológicos}

Para obter descrições que focalizassem a problemática levantada acerca da aprendizagem musical na maturidade, foi utilizada a abordagem qualitativa de caráter etnográfico escolar.

Segundo ANDRÉ (2007, p.28-29), enquanto a etnografia destaca o trabalho de campo, o contato com "práticas, hábitos, crenças, valores, linguagens, significados" de uma comunidade e a categorização na análise de dados que podem incluir situações, pessoas, locais, testemunhos, diálogos e outros mais, no processo educativo a pesquisa adapta-se ao tipo etnográfico.

A amostra que representasse parte da população alvo envolveu quatro homens e quatro mulheres, entre 50 e 64 anos, matriculados no curso de extensão que ocorreu em 2009, lembrando que nenhum participante frequentou anteriormente 
escolas especializadas ${ }^{3}$ de música. As atividades propostas, organizadas a partir de uma aula por semana durante dois módulos semestrais, objetivavam a aquisição de percepções e habilidades básicas no campo da música, a partir do treino auditivo, exercício de solfejo, leitura rítmica e escrita musical. O Termo de Consentimento Livre e Esclarecido (TCLE) que inclui as informações específicas sobre o estudo foi assinado pela professora do curso, sendo aprovado pelo Comitê de Ética em Pesquisa (COEP) juntamente com o projeto de pesquisa.

Dentre as técnicas de coleta de dados utilizadas no decorrer do trabalho questionário (como parte do estudo piloto), observação direta, análise de documentos -, as entrevistas semiestruturadas incluíram questões abertas predefinidas e perguntas improvisadas que foram adaptadas às informações dos entrevistados. Segundo SZYMANSKI, ALMEIDA e PRANDINI (2008, p.12), a entrevista representa um instrumento fundamental para a aquisição de dados qualitativos.

As entrevistas foram realizadas individualmente durante os encontros estabelecidos pelos participantes, com os testemunhos registrados em gravador digital e transcritos entre julho e setembro de 2009. Como sugestão, cada entrevistado escolheu o próprio pseudônimo, preservando, assim, o anonimato quanto aos depoimentos.

O material descritivo dos participantes se insere numa categoria ampla, sendo exposto aqui de forma resumida. Com o intuito de verificar a validade dos elementos coletados em diversas situações, justifica-se o uso da triangulação metodológica aliada ao referencial teórico e demais fontes literárias que abrangem considerações relacionadas ao processo de aprendizagem musical, necessárias para a respectiva análise.

\section{3 - Da teoria à experiência extramusical}

Quando os participantes falam sobre $O$ que significa aprender música? a ideia inclina-se a permanecer focada numa perspectiva teórica, associada à compreensão do fenômeno musical e atrelada à intenção de estudar música.

Por exemplo, para Sapoti, formada em psicopedagogia, "é impossível uma aula de música sem teoria". Ela canta em coral e, apesar de não descartar as atividades práticas, diz que o conteúdo deve abranger "ritmo, harmonia, melodia, posição das notas, o nome das claves..." - aspectos que ela avalia como teóricos. Sob seu ponto de vista, "às vezes tem muita gente que tem a prática e não tem a teoria".

Saulo, professor adjunto de História e estudante de gaita de boca, relata em seu depoimento o que pensa sobre aprender música:

Para mim, aprender seria exatamente entender o que tá escrito, por exemplo, numa partitura [...] Então, para mim, aprender, fazer esse curso, é [...] compreender as oitavas, uma série das escalas, os intervalos... Enfim, compreender o que tá sendo feito. (Saulo). 
Lane toca flauta transversal e tira as músicas de ouvido. Seu interesse é saber sobre escalas, e não mais "fingir que está lendo". Ela admite que em um curso de música será possível entender "o que é o racional da coisa".

De modo semelhante, Fripp, professor de física, comenta que sempre teve facilidade em conseguir ouvir e reproduzir uma música. Porém, ele tem vontade de aprender a ler partitura e tocar teclado para poder executar um repertório de MPB.

No caso de Baessa, ela começou o aprendizado de piano quando jovem, e após 45 anos resolveu estudar teclado, aprendendo agora "coisas da teoria" que não viu no passado.

Dora, integrante da Educação de Jovens e Adultos (EJA), diz que iniciou o curso sem qualquer conhecimento musical, pois não teve sequer oportunidade de ser alfabetizada quando jovem. Mesmo assim, ela pretende "estudar até aprender" a cantar e tocar algum instrumento.

Para o jornalista Marcos, a aprendizagem musical se inicia com a musicalização, associada à condição de aprender a utilizar a "voz ou instrumentos". Ele revela que "gostaria de aprender a tocar violão, de cantar, de poder escrever um pouco sobre música erudita".

Na opinião de Ton, aprendizado musical "é para um leigo" que precisa "conhecer o básico" por meio da teoria. Ele toca de ouvido o violão desde os 15 anos, e acredita que "só faz música quem conhece de música".

Pela concepção dos participantes, o significado de aprender música é algo que, inicialmente, se distancia da prática, levando a crer que o conhecimento musical exige um conteúdo com enfoque mais teórico. De acordo com GREEN (2005, p.3-4), a capacidade de o ouvinte perceber as qualidades do som, assim como fazer conexões que se referem a um estilo musical, envolve os "significados inerentes musicais". Em resumo, isso quer dizer que os signos - um acorde, uma nota, uma frase - e os significados percebidos na organização do som estão contidos no material da própria música. Desse modo, a cada etapa o aprendiz toma consciência do seu universo sonoro, ficando motivado a perceber novas estruturas ao ouvir músicas.

A partir dos depoimentos, podemos também salientar que a vontade primordial da maioria desses adultos que tiveram ou passam por uma experiência musical extraescolar é aprender a grafia e a leitura musical. Em nossa cultura, essa forma de entender o sistema de escrita organizado por símbolos ou códigos sonoros que representam a música sugere que a leitura de uma partitura equivale ao domínio teórico-musical. Assim, enquanto na prática de tocar um instrumento de ouvido os indivíduos aprendem, improvisam e criam suas músicas observando outras performances, persiste ainda a crença, exposta por SOUZA (1998, p.206): "se eu não sei ler música, logo não sei música." 
Segundo ainda SOUZA (1998, p.211), mesmo que haja diferentes tipos de grafia musical, a leitura de notas torna-se possível à medida que o ouvinte desenvolve a capacidade de extrair os sons de sinais escritos. A esse respeito, SWANWICK (1996, p.27) destaca que a notação ocidental ocuparia apenas uma posição de apoio na aprendizagem musical, visto que a música pode ser escrita por outros meios ou até mesmo nem ser grafada.

Considerando a faixa etária dos participantes, é provável que eles tenham uma perspectiva mais tradicional quanto à aquisição de saberes, buscando assim uma escola que ofereça o aprendizado de música. Dessa maneira, o curso escolhido por eles corresponderia aos propósitos esperados na aprendizagem musical, onde é possível aprender de forma metódica a nomear, ler e escrever notas, intervalos, ritmos, acordes, figuras musicais etc.

No entanto, é importante ressaltar que toda música tem origem em um contexto social, ligando o espaço entre diferentes indivíduos e culturas diversas (SWANWICK, 2003, p.38). Vale observar que nos relatos dos entrevistados há uma fração da experiência de vida de cada pessoa em relação à música: uns gostam de cantar, outros tocam de ouvido, outros preferem ouvir música... Apesar de os alunos não terem passado pela aprendizagem musical especializada em tempos anteriores, a maioria deles teve contato com a música a partir da infância ou da adolescência, através de práticas culturais vivenciadas no dia a dia.

Desse modo, o contexto no qual a música é originalmente produzida e sua recepção em diferentes culturas contribuem para as delineações da música. Trata-se, portanto, de significados delineados que devem ser associados aos aspectos extramusicais referentes à identidade, conceitos, expressões, valores e diversos fatores simbólicos atribuídos à música. Nesse aspecto, a música passa a representar constituintes não musicais relacionadas com o meio social e que são esboçadas metaforicamente (GREEN, 2005, p.5).

Segundo PENNA (1990, p.36), ainda que haja necessidade de se focalizar os elementos fundamentais da música, como altura, dinâmica, andamento, timbre etc., é essencial que o ouvinte antes mesmo perceba o "fato musical em si", a partir da observação e da experimentação. Desse modo, quando exploramos "ambientes e práticas" que estimulam "participação, comportamento, criatividade, ação", emerge a possibilidade de se conceber a música como agente mediador, auxiliando o indivíduo na construção de um "diálogo com a realidade" (SEKEFF, 2002, p.120). Nessa perspectiva, podemos afirmar que o processo de ir à escola aprender música é algo capaz de gerar novas experiências e modificações; no entanto, dar sentido à aprendizagem musical dependerá dos hábitos e particularidades dos alunos.

\section{4 - Música em ação}

É óbvio que cada participante decidiu saber um pouco de música, iniciando as aulas na esperança de adquirir alguma habilidade nesta área, como ler partitura e/ou tocar algum instrumento musical. Entretanto, a tarefa de aprender música também se 
mostrou ligada à vivência musical do aprendiz fora da escola, em seu ambiente familiar e cotidiano. De certa maneira, esse detalhe gerou contradição. Se, por um lado, os alunos afirmam que sentem falta da teoria na sua formação musical, em outro momento demonstram a preferência pela atividade prática.

Marcos, por exemplo, reconhece a importância dos exercícios teóricos para decifrar uma partitura, mas enfatiza a experimentação. Para ele, a prática musical tem a ver com o fazer música: "Fazer música é cantar, tocar um instrumento, compor, acompanhar, participar de um coral, participar de uma orquestra... [...] Isso depende de algum conhecimento, não da teorização".

Em relação à apreciação, Lane comenta que deveria haver mais prática de audição durante as aulas, porque as pessoas, geralmente, "não têm o hábito de ouvir". Porém, ela sugeriria um repertório diversificado, sem ficar "só no Clássico, no Barroco..." Marcos, que se considera um "ouvinte assíduo" também espera aprender melhor a apreciar a música e aprimorar sua percepção auditiva.

Segundo GAINZA (1988, p.117), a "educação do ouvido" contribui para o desenvolvimento da mente musical, de acordo com o que o ouvido pode absorver da música. Isso indica que quanto maior a capacidade perceptiva e a familiaridade que o indivíduo tiver com o estilo de música, provavelmente mais positiva será sua resposta à experiência musical (GREEN, 2005, p.9).

Para Baessa, que gosta muito de dançar, o vínculo corpo/música é "bom e vital para quem já ultrapassou a faixa dos 60". Ela observa que "o trabalho corporal unido à música seria ideal". De acordo com GAINZA (1988, p.102), ao se compreender "movimento como sinônimo de vida", e não apenas de caráter musical e sonoro, abrem-se perspectivas para se promover variadas respostas comportamentais.

Conforme PENNA (1990, p.37), a relação entre sujeito e ação por meio da música assume o caráter de aproximar o indivíduo da música e levá-lo a "expressar-se criativamente através de elementos sonoros", independentemente do domínio teórico e da faixa etária. Sob esta ótica, quando associamos o fazer música a uma prática de aprendizagem que revela as mais variadas expressões, vem à tona o que pode ser realizado em sala de aula, e principalmente, como os alunos na maturidade participam e se comunicam entre si, seja a partir da voz, do gesto, da dança e performance.

Outro recurso considerado importante para o aprendizado musical e sugerido pelos participantes refere-se às atividades lúdicas, que envolvem interação e criatividade.

$\mathrm{Na}$ opinião de Marcos, "uma prática criativa, lúdica, com mais intensidade, pode ajudar a render mais" e "combater a inibição", pelo fato de ser "mais estimulante do que a parte teórica". 
Sapoti admite que o entretenimento musical adapta-se a qualquer faixa etária. Para ela, quando o conteúdo é adaptado de uma forma lúdica, "a gente consegue entender muito melhor e consegue também aprender [...]"

Do ponto de vista literário, ILARI (2003, p.15) afirma que os jogos musicais "podem constituir uma fonte rica de aprendizado", incentivando o divertimento e a participação ativa do educando. Todavia, quando um professor associa o jogo aos processos criativos e pedagógicos em uma aula de música para adultos, pode haver alguém que fale: "Ah! isso aí é coisa de criança!" Talvez os adultos sintam receio de se exporem a uma atividade lúdica por causa de uma suposta infantilização, apesar dos múltiplos exemplos que nos permitem analisar que não há limite de idade para tirar proveito de jogos e brincadeiras. Esse fato revela a necessidade de se adequar a estratégia pedagógica à situação do aluno na fase da maturidade.

Portanto, torna-se conveniente conciliar o treinamento auditivo a partir da apreciação musical, a expressividade do indivíduo e os elementos básicos da música, numa integração dinâmica de recepção e de atitude musical. Afinal,

\begin{abstract}
o indivíduo receptivo à música começa a sentir e a compreender, motivado por uma mobilização interior que favorece uma musicalidade ativa, que lhe permite informar suas experiências, extravasar suas emoções e refletir sobre seus interesses e gostos musicais (CIRINO, 2011, p.299).
\end{abstract}

Neste caso, a musicalização, a partir de uma orientação adequada no processo educacional, pode abrir espaço para novas experiências que proporcionam o conhecimento resultante da articulação entre prática e teoria.

\title{
5 - Aprender fazendo música
}

Provavelmente o hábito de ouvir ou apreciar música no cenário cotidiano não seja o suficiente na perspectiva do adulto que pretende aprender música. Ton, por exemplo, comenta: "Não quero só cantar, não quero só tocar, eu quero é aprender fazer música". Contudo, é preciso associar a percepção dos parâmetros musicais e a descoberta de conceitos com as experiências de aprendizagem informal ou cotidiana de música. Para Gainza (1988, p.34), esse elo corresponde à articulação de sentidos, em que a música é para as pessoas não somente o objeto sonoro, mas também aquilo que simboliza ou representa algo.

Isso indica que a partir da ação musicalizadora vivenciada pelo aluno, descortina-se uma diversidade de sons capazes de ativar suas habilidades cognitivas. Tal processo permite ao aluno reagir ao captar os sons, escutá-los de modo consciente para entender o que está sendo tocado, e ampliar habilidades musicais como percepção auditiva, distinção dos estilos de música, uso da leitura e da grafia dos sons e do silêncio.

Segundo SLOBODA (2008, p.257;284), a "habilidade musical é adquirida através da interação com um meio musical", estando sujeita à herança genética e ao contexto sociocultural do indivíduo; e estende-se pela fase adulta por meio da prática musical. 
Nesse aspecto, vale frisar a importância da cognição quando se trata da organização dos materiais sonoros, visto que possibilita o raciocínio do indivíduo ao analisar a experiência musical.

Considerando, pois, o vínculo entre instrução teórica e experiência no âmbito da aprendizagem musical, SWANWICK explica:

Aprendizagem é o resíduo da experiência. [...] A compreensão musical reside numa dimensão diferente das atividades musicais por meio das quais esse entendimento pode ser revelado e desenvolvido - compondo ou improvisando, tocando a música de outras pessoas ou respondendo quando ouvimos música. (SWANWICK, 2003, p.94-95).

Portanto, a concepção sobre aprendizagem musical faz parte da realidade de cada aluno, da subjetividade e de suas perspectivas em relação ao aprendizado musical, levando em conta que os participantes trazem saberes de experiência, provenientes de vivências musicais diversificadas e de reflexões que podem ser desenvolvidas em diferentes processos de educação musical. De todo modo, quanto mais oportunidade de participação se der ao aprendiz adulto, e quanto mais motivador for o ambiente de aula, mais rica poderá ser a construção do conhecimento musical, apto para compartilhar situações que implicam criação, apreciação e expressão; ou seja, fazer música.

\section{6 - Desafios para o aprendizado musical}

Naturalmente, durante o envelhecimento humano o organismo passa por um processo de mudança que se reflete nas estruturas físicas, nas manifestações cognitivas, assim como na "percepção subjetiva dessas transformações" (PARENTE, 2006, p.23). Sendo assim, os indícios de alguma alteração nos processos intelectuais no decorrer da maturidade podem limitar a capacidade de o indivíduo adquirir novas habilidades, ocasionando lentidão e dificuldade para a resolução de problemas.

Lane, por exemplo, que nasceu em 1958, já pensou em desistir do estudo de música, ao perceber que sua memória não é mais como a de um adolescente. Baessa, com 64 anos, também comenta: "Minha memória não é mais aquela!" Ton, apesar de repetir o curso, explica: "[...] a idade também dificulta, pois o cérebro já não capta tanto quanto no tempo em que eu era mais novo. [...] Já tive até para desanimar, mas eu resolvi ir em frente".

Com o avanço normal da idade as perdas cognitivas implicam o declínio das capacidades intelectuais do sujeito, atingindo o processamento da informação e da memória. Tal mudança diz respeito ao envelhecimento primário, categorizado como normal, porém não significa doença ou deficiência funcional do indivíduo (NERI e CACHIONE, 2004, p.119; grifo do autor). Nesse caso, há um declínio da criatividade, afirma o Dr. DHARMA KHALSA (2005, p.132), pois esta se encontra estreitamente ligada à memória. 
Segundo SHAIE, citado por NERI e CACHIONE (2004, p.119), as perdas da "inteligência fluida", responsável pelo "processamento da informação e da memória" podem ser compensadas pela "inteligência cristalizada", oriunda de capacidades associadas a "fatores educacionais e socioculturais" em experiência de vida. Por isso, através da memória o indivíduo pode manter o senso de uma contínua trajetória de vida capaz de retratar até mesmo sua experiência musical (RUUD, 1998, p.44).

Nesse sentido, as mudanças típicas do envelhecimento

[...] são realidades heterogêneas, isto é, variam conforme os tempos históricos, as culturas e subculturas, as classes sociais, as histórias de vida pessoais, as condições educacionais, os estilos de vida, os gêneros, as profissões e as etnias dentre outros elementos que conformam as trajetórias de vida dos indivíduos e grupos. (NERI; CACHIONE, 2004, p.120-121).

Desse modo, é necessário adequar as propostas metodológicas ao interesse e à capacidade do aprendiz adulto. De acordo com LUZ (2008, p.25), o trabalho que envolve a aprendizagem de música na maturidade deve ser considerado instrumento relevante no desenvolvimento das faculdades humanas, porque além de abranger aspectos afetivos e sociais, contribui para o "desenvolvimento da memória e do raciocínio lógico matemático". Portanto, o envolvimento do aprendiz em determinada atividade de música se molda de acordo com as possibilidades e condições existentes, seja em relação à prática musical cotidiana que poderá ser desenvolvida em sala de aula ou à cognição, que abrange reflexão e análise.

\section{7 - Finalizando}

A princípio, o entendimento dos alunos maduros sobre a aprendizagem de música vincula-se à teoria, considerada por eles como elemento essencial para a aquisição de habilidades musicais, seja no parâmetro auditivo, instrumental e/ou notacional. Observa-se, porém, que a maioria dos alunos gosta mais da prática em sala de aula. Estaria esta prática isolada da teoria musical?

Se, por um lado, a teoria geralmente compreende solfejo, leitura rítmica, notação musical, treinamento auditivo etc., por outro lado, exercícios como ação combinada de ritmos, audição de arpejos, manipulação de instrumentos musicais, entonação de escalas também são reconhecidos como prática pedagógico-musical.

Cumpre lembrar que a ideia de prática no ensino de música pode ser vista por muitas pessoas como atividade separada do estudo teórico, ou equivalente apenas à experiência de cantar ou tocar um instrumento. No entanto, é importante refletir sobre a relação entre o discurso teórico e a prática, pois ambos fazem parte do processo de aprendizagem musical.

Embora os adultos maduros tenham interesse em ler partitura, tocar determinado instrumento e/ou solfejar, a vivência musical cotidiana articulada aos processos de aprendizagem formal deve ser valorizada, sendo que o sentido da música varia de acordo com as diversidades e experiências individuais. Ou seja, enquanto a 
aprendizagem musical possibilita ao indivíduo construir novos conhecimentos, a música permanece integrada ao contexto sociocultural e à natureza das pessoas. Portanto, se a música não for familiar, provavelmente ela não será apreciada pelo ouvinte, que pode considerá-la "casual ou incoerente", reitera GREEN (2005, p.11).

Conforme os relatos dos participantes, eles gostam de conviver com a música e continuam em busca de novidade, bem como tiveram a chance de perceber que as atividades em sala ganhavam caráter inédito à medida que um elemento musical era descoberto. Como exemplo, Saulo descobriu que a composição musical possui estrutura; Marcos considerou interessante a similaridade entre música, aritmética e matemática; Dora aprendeu a distinguir as claves de Sol e Fá; Lane decifrou a divisão de um compasso simples...

Nesse sentido, descobrir novas ideias pressupõe uma participação ativa do aprendiz, porque abarca o potencial daquele que sabe ou que deseja saber algo num processo que vai além da simples reprodução de conteúdos. Ademais, colocar a música em ação diz respeito à prática social, emoção e pensamento (DENORA, 2003, p.165). Enfim, se a competência musical permanece adormecida, ela pode emergir na ação daquele que tem a motivação e a iniciativa de fazer música. Isso nos faz pensar que o aprendizado musical implica teoria e prática. Desse modo, o professor de música deve estar preparado para lidar com a diversidade cultural e métodos flexíveis que incentivem (re)criar ideias.

Ainda que surjam mudanças relacionadas aos aspectos fisiológicos e psíquicos dos adultos maduros, parece não existir período restrito para se musicalizar as pessoas. Assim, torna-se favorável combinar propostas motivadoras de inovação, bem-estar, percepção, interação, que buscam aproximar a pessoa da música. Como explana SWANWICK (2003, p.40), a música "possui um papel na reprodução cultural e afirmação social", além do "potencial para promover o desenvolvimento individual, a renovação cultural, a evolução social, a mudança". Dentro desse panorama, compete aos educadores musicais orientar metodologias e adequar o conteúdo programático das aulas para alunos na maturidade, realçando uma aprendizagem qualitativa capaz de gerar novas oportunidades educativas.

\section{Referências}

ANDRÉ, M. E. D. A. Etnografia da prática escolar. 13. ed. Campinas: Papirus, 2007.

CIRINO, A. C. Apreciação musical: um processo ativo na musicalização de adultos. In: CONGRESSO DA ASSOCIAÇÃO NACIONAL DE PESQUISA E PÓS-GRADUAÇÃO EM MÚSICA, 21., 2011, Uberlândia. Anais... Uberlândia: ANPPOM, 2011. p.296-302.

DEBERT, G. G. A reinvenção da velhice. São Paulo: Edusp, 2004.

DENORA, T. Music sociology: getting the music into the action. British Journal of Music Education, Cambridge, v.20, n.2, p.165-177, 2003.

FONTERRADA, M. T. O. Diálogo interáreas: o papel da educação musical na atualidade. Revista da ABEM, Porto Alegre, v.18, p.27-33, out. 2007.

GAINZA, Violeta H. Estudos de psicopedagogia musical. Tradução Beatriz A. Cannabrava. São Paulo: Summus, 1988.

GREEN, Lucy. Meaning, autonomy and authenticity in the music classroom. Londres: Institute of Education, University of London, 2005. 
ILARI, B. A música e o cérebro: algumas implicações do neurodesenvolvimento para a educação musical. Revista da ABEM, Porto alegre, v.9, p.7-16, set. 2003.

KHALSA, D. S. Longevidade do cérebro. Tradução Sylvia Bello. Rio de Janeiro: Objetiva, 2005.

LUZ, M. C. Educação musical na maturidade. São Paulo: Editora Som, 2008.

NERI, A. L.; CACHIONI, M. Velhice bem-sucedida e educação. In: NERI, A. L.; DEBERT, G. G. (Orgs.). Velhice e sociedade. Campinas: Papirus, 2004. p.113-140.

PARENTE, M. A. M. P. Cognição e envelhecimento. São Paulo: Artmed, 2006.

PENNA, M. Reavaliações e buscas em musicalização. São Paulo: Loyola, 1990.

RUUD, E. Music Therapy: improvisation, communication and culture. Barcelona: Publishoes, 1998.

SEKEFF, M. L. Da música: seus usos e recursos. São Paulo: UNESP, 2002.

SLOBODA, J. A mente musical: a psicologia cognitiva da música. Tradução Beatriz llari e Rodolfo Ilari. Londrina: EDUEL, 2008.

SOUZA, J. Sobre as múltiplas formas de ler e escrever música. In: NEVES, I.; SOUZA, J.; SCHAFFER, N. et al. (Orgs.). Ler e escrever: compromisso de todas as áreas. Porto Alegre: Editora da UFRGS, 1998. p.205-214.

SWANWICK, K. Ensinando música musicalmente. São Paulo: Moderna, 2003.

Music education before the National Curriculum. In: SPRUCE, Gary (Ed.). Teaching music. Londres: Routledge, 1996. p.21-48

SZYMANSKI, H.; ALMEIDA, L. R.; PRANDINI, R. C. A. R. A entrevista na pesquisa em educação: a prática reflexiva. 2. ed. Brasília: Editora Plano, 2008.

\section{Notas}

1 Para a pesquisa, o recorte etário refere-se à população de adultos maduros caracterizada pela fase intermediária que ultrapassa a do adulto jovem e antecede a Terceira Idade. Considerando a heterogeneidade nos padrões de classificação de idades, a população de idosos geralmente é definida a partir dos 60 anos.

2 Parte do livro Reavaliações e buscas em musicalização, da autora MAURA PENNA, foi publicada de forma original no livro Música(s) e seu ensino (2008. p.27-47).

3 Escolas especializadas - escolas livres de música, conservatórios, cursos técnicos e superiores, nas modalidades licenciatura e bacharelado (FONTERRADA, 2007, p.28).

Andréa Cristina Cirino é Mestre em Música pela Universidade Federal de Minas Gerais (2010). Concluiu os cursos de Especialização em Educação Musical e Ensino Instrumental na Escola de Música da Universidade do Estado de Minas Gerais (2005). Possui Licenciatura em Música (1994) e Bacharelado em Clarinete (1990) pela UFMG. Lecionou as disciplinas de Prática Instrumental, Educação Musical e Organologia no Centro de Ensino Técnico da Polícia Militar/MG (1999-2008). Administra aulas de flauta-doce e atua profissionalmente como clarinetista em eventos. Com experiência na área de Artes, dedica-se aos seguintes temas: musicalização, performance e identidade musical. 